\title{
Aneuploid progenies of triploid hybrids between diploid and tetraploid loach Misgurnus anguillicaudatus in China
}

\author{
Ya-Juan $\mathrm{Li}^{1} \cdot{\text { Yang-Chun } \mathrm{Gao}^{2} \cdot \mathrm{He} \mathrm{Zhou}^{1} \cdot \mathrm{Hai}-\mathrm{Yan} \mathrm{Ma}^{1} \cdot \mathrm{Zhong} \text { Qiao Lin }}^{1}$ • \\ Tian-Yu Ma ${ }^{1} \cdot \mathrm{Yi} \mathrm{Sui}^{1} \cdot \mathrm{Katsutoshi}^{\mathrm{Arai}^{3}}$
}

Received: 21 March 2016/Accepted: 19 September 2016/Published online: 22 September 2016

(c) Springer International Publishing Switzerland 2016

\begin{abstract}
Triploid Chinese loach, Misgurnus anguillicaudatus, hybrids between tetraploids from Hubei Province and diploids from Liaoning Province were mated with either diploid wild-type or triploid hybrids to analyze viability and ploidy of the resultant progenies. Both triploid males and females generated fertile gametes, but progenies from the crosses using gametes of triploid hybrids did not survive beyond the larval stages. In crosses between wildtype diploid females and triploid hybrid males, embryos ranging from $2.2 \mathrm{n}$ to $2.6 \mathrm{n}$ were predominant with a mode of either $2.4 \mathrm{n}$ (chromosome numbers 59, 60, 61) or $2.5 \mathrm{n}$ (chromosome numbers 62, 63). Those from the crosses between triploid hybrid females and diploid males gave a modal ploidy level at approximately $2.5 \mathrm{n}$ in one case, but a shift to a higher ploidy level was observed in other embryos. In the progenies between triploid hybrid females and males, the ploidy level at approximately 3.0n (chromosome numbers $74,75,76$ ) was most frequent. The cytogenetic results of the progenies suggest the production of aneuploid gametes with a modal ploidy level at
\end{abstract}

Electronic supplementary material The online version of this article (doi:10.1007/s10709-016-9928-8) contains supplementary material, which is available to authorized users.

Katsutoshi Arai

araikt@fish.hokudai.ac.jp

1 Key Laboratory of Mariculture and Stock Enhancement in North China's Sea, Ministry of Agriculture, Dalian Ocean University, Dalian 116023, China

2 Research Center for Eco-Environmental Science, Chinese Academy of Science, 18 Shuangqing Road, Haidian District, Beijing 100085, China

3 Faculty and Graduate School of Fisheries Sciences, Hokkaido University, 3-1-1, Minato, Hakodate, Hokkaido 041-8611, Japan approximately $1.5 \mathrm{n}$ in triploid hybrids. However, a shift to higher chromosome numbers in gametes was observed in certain cases, suggesting the involvement of mortality selection of gametes and/or zygotes with lower chromosome numbers.

Keywords Bivalent · Gamete - Meiosis · Polyploid · Trivalent · Univalent

$\begin{array}{ll}\text { Abbreviation } \\ \text { Ag-NORs } & \text { silver staining nucleolus organizer regions. } \\ \text { CMA }_{3} & \text { chromomycin } \mathrm{A}_{3} . \\ \text { CN } & \text { chromosome number. } \\ \text { DA } & \text { distamycin A. } \\ \text { DAPI } & 4^{\prime} 6 \text {-diamidino-2-phenylindole. } \\ \text { FISH } & \text { fluorescence in situ hybridization. }\end{array}$

\section{Introduction}

Meiotic chromosome configurations give insights into the pairing behavior of extra homologous chromosomes as well as the reproductive capacity of resultant gametes in polyploid animals. However, the relationship between meiotic configurations of chromosomes and gametogenesis has not well been clarified both in either natural or induced triploid teleosts.

In several auto- and allotriploid fishes, which were artificially induced by inhibiting the second polar body release just after fertilization, gametes with a ploidy level of approximately $1.5 \mathrm{n}$ have been reported (Allen et al. 1986; Benfey et al. 1986; Ueda et al. 1987, 1991; Van Eenennaam et al. 1990; Zhang and Arai 1999; Gomelsky et al. 2015). Among them, however, meiotic configurations have not been well investigated except for induced triploid 
loach Misgurnus anguillicaudatus, in which about 25 bivalents (IIs hereafter) and 25 univalent (Is hereafter) were observed (Zhang and Arai 1999).

In China, bisexually reproducing diploid $(2 \mathrm{n}=50)$-tetraploid $(4 \mathrm{n}=100)$ complex exists and thus triploid hybrids are easily produced by cross-breeding ( $\mathrm{Li}$ et al. 2008, 2010, 2011, 2012, 2013). Since we observed that meiotic cells most frequently exhibited 25IIs and 25Is in triploid hybrids, we predicted the formation of gametes with a mode at $1.5 \mathrm{n}$ ( 37 or 38 ) chromosomes as a result of equal segregation of 25IIs and random segregation of 25Is (Li et al. 2015).

In the present study, we examined the chromosomes (ploidy level) and viability of progenies from inter-crosses between (1) diploid females and triploid males, (2) triploid females and diploid males, and (3) triploid females and triploid males, to elucidate the relationship between the complicated meiotic configurations and gametogenesis in triploid Chinese loach hybrids.

\section{Materials and methods}

Triploid hybrids were reciprocally produced between tetraploids from Hubei Province, China and diploids from Liaoning Province, as previously described in $\mathrm{Li}$ et al. (2012, 2013, 2015). Using two females and two males selected from each triploid (tetraploid females $\times$ diploid males) hybrid, diploid, and tetraploid brood-stock, we produced the two sets (nos. 1 and 2) of following progenies in 2012: $2 \mathrm{n}$ (hereafter female first) $\times 2 \mathrm{n}$ (male), $2 \mathrm{n} \times 4 \mathrm{n}$, $4 n \times 2 n, 4 n \times 4 n, 2 n \times 3 n, 3 n \times 2 n$, and $3 n \times 3 n$. Using two females and two males selected from each triploid (diploid females $\times$ tetraploid males) hybrid and diploid brood-stock, we produced two sets (nos. 3 and 4) of $2 n \times 2 n, 2 n \times 3 n, 3 n \times 2 n$ and $3 n \times 3 n$ progenies in 2014 .

At approximately $0.5 \mathrm{~h}$ post fertilization, the diameter of fertilized eggs $(n=30)$ from the $2 n \times 2 n, 3 n \times 2 n$ and $3 n \times 3 n$ crosses was measured using a digital caliper on photographed images in accordance with the procedures described in Li et al. (2012) and then compared statistically ( $t$ test).

Testicular cells were examined by flow-cytometry in 15 approximately 4-year-old triploid (tetraploid females $\times$ diploid males) hybrid males according to the methods described in Oshima et al. (2005) and Yoshikawa et al. (2007). As a control, one diploid and one tetraploid male of the same age were randomly taken to sample testicular cells.

Survival parameters were estimated as described in $\mathrm{Li}$ et al. (2013). Fertilization rate was calculated as the proportion of cleaved eggs relative to the initial number of eggs. Hatching rate was calculated as the proportion of hatched eggs relative to the initial number of eggs. Normal rate was calculated as the proportion of normal larvae relative to the number of hatched larvae. Survival rate at 7 days after hatching was calculated as the proportion of surviving larvae relative to the number of hatched larvae. Rearing water was changed daily after the larvae were first fed Artemia.

Chromosome preparation was individually conducted on each optic vesicle stage embryo after manually removing the yolk in physiological saline under a stereoscopic microscope. Chromosome preparation procedures were the same as those described in Li et al. (2013). Chromosome counting was made on conventional Giemsa-stained metaphases on a slide directly under a microscope and/or on their photographed images. In the progenies, the modal chromosome number was determined in each embryo. Karyotyping was conducted according to Levan et al. (1964). Differential staining with $\mathrm{CMA}_{3} / \mathrm{DA} / \mathrm{DAPI}$ (Schweizer 1976; Schweizer et al. 1978) and the Ag-NOR method (Howell and Black 1980) was applied to the chromosome slides in accordance with $\mathrm{Li}$ et al. (2010). FISH using human $5.8 \mathrm{~S}+28 \mathrm{~S}$ rDNA sequences as a probe was applied according to Li et al. (2010).

\section{Results}

\section{Survival potential of triploid hybrid progenies}

Parameters for zygote survival capacity are shown in Table 1. Fertilization rates were $>80 \%$ in all of the crosses using the eggs and sperm of wild-type diploid and natural tetraploid loaches. In contrast, reduced fertilization rates were always observed in crosses using triploid hybrid eggs and/or sperm. Hatching rates were $>80 \%$ in the $2 n \times 2 n$, $2 n \times 4 n, 4 n \times 2 n$ and $4 n \times 4 n$ crosses, but approximately $14-67 \%$ hatching rates were recorded in $2 \mathrm{n} \times 3 \mathrm{n}$, $3 n \times 2 n$ and $3 n \times 3 n$. Almost all $(>92 \%)$ of the hatched larvae were normal in the $2 n \times 2 n, 2 n \times 4 n, 4 n \times 2 n$ and $4 n \times 4 n$ crosses, but reduced normal rates (41-55\%) were recorded in most of the crosses using triploid hybrid eggs and/or sperm except for $3 n \times 2 n$ crosses in 2014 (81-83\%). Survival rates of 7-day-old larvae after hatching were relatively high in the $2 n \times 2 n, 2 n \times 4 n, 4 n \times 2 n$ and $4 n \times 4 n$ crosses (about 84-98\%), while reduced rates were recorded in the triploid hybrid progenies $(3-33 \%)$. The larvae from the $2 n \times 2 n, 2 n \times 4 n, 4 n \times 2 n$ and $4 n \times 4 n$ crosses survived beyond the beginning of feeding and most exhibited further growth. However, all the survivors from the $3 n \times 2 n, 2 n \times 3 n$ and $3 n \times 3 n$ crosses exhibited external malformations including microcephaly, microphthalmia, edema, dwarfism, curved trunk and tail, and so on (Fig. 1) and no larvae survived for more than 10 days after hatching. 
Table 1 Number of eggs, fertilization rate, hatching rate, normal rate and survival rate at 7 days after hatching in the different crosses using diploid, tetraploid and triploid (diploid female $\times$ tetraploid male) loaches in 2012 and 2014

\begin{tabular}{|c|c|c|c|c|c|c|}
\hline Year & Cross & $\begin{array}{l}\text { No. of } \\
\text { eggs }\end{array}$ & $\begin{array}{l}\text { Fertilization } \\
\text { Rate }(\%)\end{array}$ & $\begin{array}{l}\text { Hatching } \\
\text { Rate }(\%)\end{array}$ & $\begin{array}{l}\text { Normal } \\
\text { Rate }(\%)\end{array}$ & $\begin{array}{l}\text { Survival rate at } 7 \text { days } \\
\text { after hathcing }(\%)\end{array}$ \\
\hline \multirow[t]{21}{*}{2012} & $2 n \times 2 n-1$ & 1562 & 87.00 & 82.10 & 94.30 & 83.60 \\
\hline & $2 n \times 2 n-2$ & 1663 & 87.90 & 80.60 & 91.70 & 83.50 \\
\hline & Mean $\pm \mathrm{SD}$ & & $87.45 \pm 0.64^{\mathrm{a}}$ & $81.35 \pm 1.06^{\mathrm{b}}$ & $93.00 \pm 1.84^{\mathrm{a}}$ & $83.55 \pm 0.07^{\mathrm{d}}$ \\
\hline & $2 n \times 4 n-1$ & 1509 & 80.73 & 89.25 & 96.22 & 92.31 \\
\hline & $2 n \times 4 n-2$ & 770 & 82.21 & 86.21 & 96.65 & 91.55 \\
\hline & Mean \pm SD & & $81.47 \pm 1.05^{\mathrm{a}}$ & $87.73 \pm 2.15^{\mathrm{ab}}$ & $96.44 \pm 0.30^{\mathrm{a}}$ & $91.93 \pm 0.54^{\mathrm{b}}$ \\
\hline & $4 n \times 2 n-1$ & 1521 & 81.22 & 91.14 & 91.82 & 87.98 \\
\hline & $4 n \times 2 n-2$ & 1021 & 80.13 & 89.11 & 92.21 & 87.33 \\
\hline & Mean $\pm \mathrm{SD}$ & & $80.68 \pm 0.77^{\mathrm{a}}$ & $90.13 \pm 1.43^{\mathrm{a}}$ & $92.02 \pm 0.28^{\mathrm{a}}$ & $87.66 \pm 0.46^{\mathrm{c}}$ \\
\hline & $4 n \times 4 n-1$ & 640 & 83.60 & 80.60 & 96.80 & 98.37 \\
\hline & $4 n \times 4 n-2$ & 804 & 82.70 & 86.60 & 96.70 & 96.86 \\
\hline & Mean $\pm \mathrm{SD}$ & & $83.15 \pm 0.64^{\mathrm{a}}$ & $83.60 \pm 4.24^{\mathrm{b}}$ & $96.75 \pm 0.07^{\mathrm{a}}$ & $97.62 \pm 1.07^{\mathrm{a}}$ \\
\hline & $2 n \times 3 n-1$ & 566 & 57.10 & 32.00 & 56.00 & 31.90 \\
\hline & $2 n \times 3 n-2$ & 1066 & 70.50 & 37.80 & 53.60 & 34.20 \\
\hline & Mean \pm SD & & $63.8 \pm 9.48^{\mathrm{b}}$ & $34.9 \pm 4.10^{\mathrm{c}}$ & $54.8 \pm 1.70^{\mathrm{b}}$ & $33.05 \pm 1.63^{\mathrm{e}}$ \\
\hline & $3 n \times 2 n-1$ & 399 & 33.80 & 16.30 & 48.10 & 7.41 \\
\hline & $3 n \times 2 n-2$ & 421 & 31.60 & 16.20 & 51.10 & 9.02 \\
\hline & Mean \pm SD & & $32.7 \pm 1.56^{\mathrm{c}}$ & $16.25 \pm 0.07^{\mathrm{d}}$ & $49.6 \pm 2.12^{\mathrm{b}}$ & $8.22 \pm 1.14^{\mathrm{f}}$ \\
\hline & $3 n \times 3 n-1$ & 331 & 34.70 & 16.00 & 45.20 & 7.82 \\
\hline & $3 n \times 3 n-2$ & 644 & 32.90 & 12.40 & 37.70 & 7.07 \\
\hline & Mean \pm SD & & $33.8 \pm 1.27^{\mathrm{c}}$ & $14.2 \pm 2.55^{\mathrm{d}}$ & $41.45 \pm 5.30^{\mathrm{c}}$ & $7.45 \pm 0.53^{\mathrm{f}}$ \\
\hline \multirow[t]{12}{*}{2014} & $2 n \times 2 n-3$ & 1329 & 87.13 & 88.17 & 91.77 & 82.56 \\
\hline & $2 n \times 2 n-4$ & 1560 & 88.91 & 90.12 & 94.24 & 85.36 \\
\hline & Mean \pm SD & & $88.02 \pm 1.26^{\mathrm{a}}$ & $89.15 \pm 1.38^{\mathrm{a}}$ & $93.01 \pm 1.75^{\mathrm{a}}$ & $83.96 \pm 1.98^{\mathrm{a}}$ \\
\hline & $2 n \times 3 n-3$ & 1458 & 58.30 & 55.29 & 56.6 & 3.41 \\
\hline & $2 n \times 3 n-4$ & 1617 & 64.56 & 59.39 & 53.87 & 3.07 \\
\hline & Mean $\pm \mathrm{SD}$ & & $61.43 \pm 4.43^{\mathrm{c}}$ & $57.34 \pm 2.90^{\mathrm{c}}$ & $55.24 \pm 1.93^{\mathrm{c}}$ & $3.24 \pm 0.24^{\mathrm{b}}$ \\
\hline & $3 n \times 2 n-3$ & 589 & 74.87 & 65.53 & 81.31 & 4.08 \\
\hline & $3 n \times 2 n-4$ & 632 & 73.26 & 67.60 & 83.39 & 3.67 \\
\hline & Mean \pm SD & & $74.07 \pm 1.14^{\mathrm{b}}$ & $66.57 \pm 1.46^{\mathrm{b}}$ & $82.35 \pm 1.47^{\mathrm{b}}$ & $3.88 \pm 0.29^{\mathrm{b}}$ \\
\hline & $3 n \times 3 n-3$ & 667 & 55.62 & 52.02 & 47.67 & 3.50 \\
\hline & $3 n \times 3 n-4$ & 656 & 58.69 & 57.66 & 53.15 & 4.42 \\
\hline & Mean \pm SD & & $57.16 \pm 2.17^{\mathrm{c}}$ & $54.84 \pm 3.99^{c}$ & $50.41 \pm 3.87^{\mathrm{c}}$ & $3.96 \pm 0.65^{\mathrm{b}}$ \\
\hline
\end{tabular}

Different lowercase letters in the same row indicated significant differences $(p<0.05)$ among different crosses; and same letters indicated no significance $(p>0.05)$

\section{Triploid hybrid egg sizes}

The mean egg diameters were $0.83 \pm 0.02 \mathrm{~mm}(\mathrm{SD})$ in $2 \mathrm{n} \times 2 \mathrm{n}-1, \quad 0.94 \pm 0.04 \mathrm{~mm} \quad$ in $3 \mathrm{n} \times 2 \mathrm{n}-1$ and $0.94 \pm 0.03 \mathrm{~mm}$ in $3 \mathrm{n} \times 3 \mathrm{n}-1$ crosses (Fig. S1). Both $3 n \times 2 n-1$ and $3 n \times 3 n-1$ had significantly larger egg diameters than the control $2 \mathrm{n} \times 2 \mathrm{n}-1 \quad(p<0.05)$. Thus, eggs laid by triploid females were larger than those laid by wild-type diploids.

\section{Triploid hybrid chromosomes}

Here, we confirmed the genomic constitution of triploid hybrids based on chromosome numbers, karyotypes, and NOR numbers detected by differential staining and FISH. In 20 embryos from each of the $2 n \times 2 n, 2 n \times 4 n, 4 n \times 2 n$ and $4 \mathrm{n} \times 4 \mathrm{n}$ crosses, chromosomes were individually counted (Table S1). Out of 543 metaphases from $2 n \times 2 n$ embryos $(n=20), 266$ cells had 50 chromosomes. Out of 
Fig. 1 External appearance of (a) normal larvae from crosses $(2 \mathrm{n} \times 2 \mathrm{n}, 2 \mathrm{n} \times 4 \mathrm{n}, 4 \mathrm{n} \times 2 \mathrm{n}$ and $4 n \times 4 n$ ) using gametes of wild-type diploid and those of natural tetraploid loach and (b) abnormal larvae from crosses $(3 n \times 2 n, 2 n \times 3 n$ and $3 n \times 3 n)$ using gametes of triploid hybrids and those of wild-type diploids. Scales denote $10 \mu \mathrm{m}$
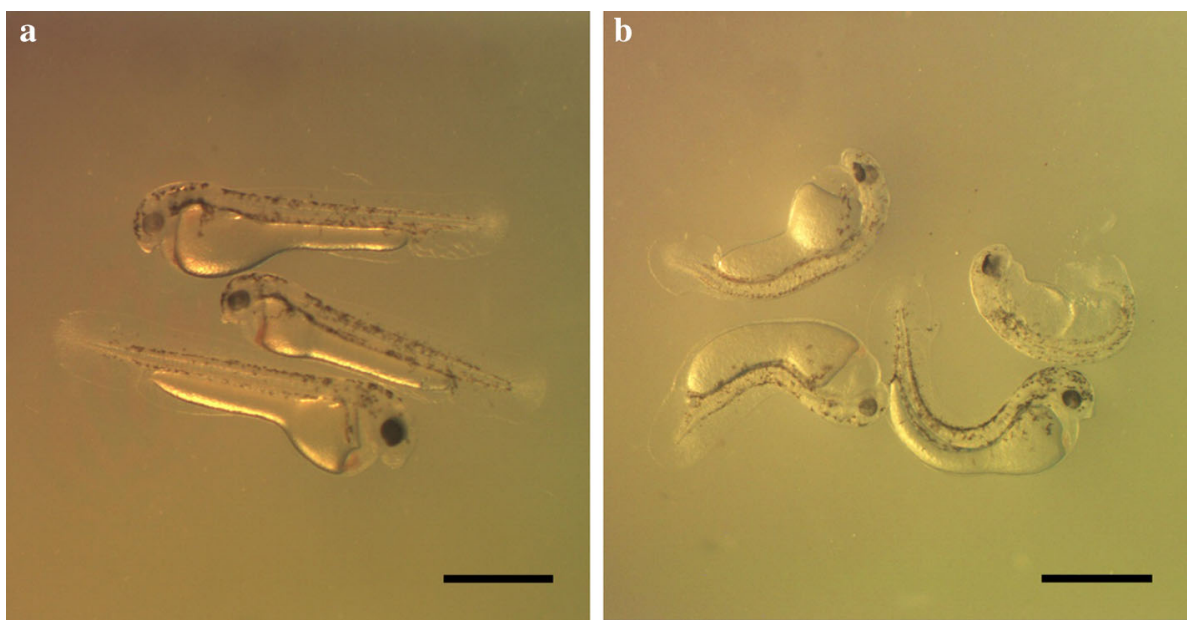

594 metaphases from $2 n \times 4 n$ embryos $(n=20), 272$ cells had 75 chromosomes. Out of 529 metaphases from $4 n \times 2 n$ embryos $(n=20), 267$ cells had 75 chromosomes. Out of 463 metaphases from $4 n \times 4 n$ embryos $(n=20), 249$ cells had 100 chromosomes. Thus, $2 \mathrm{n} \times 2 \mathrm{n}, 2 \mathrm{n} \times 4 \mathrm{n}, 4 \mathrm{n} \times 2 \mathrm{n}$ and $4 n \times 4 n$ crosses generated diploid $(2 n=50)$, triploid $(3 n=75)$, triploid $(3 n=75)$ and tetraploid $(4 n=100)$ progenies, respectively.

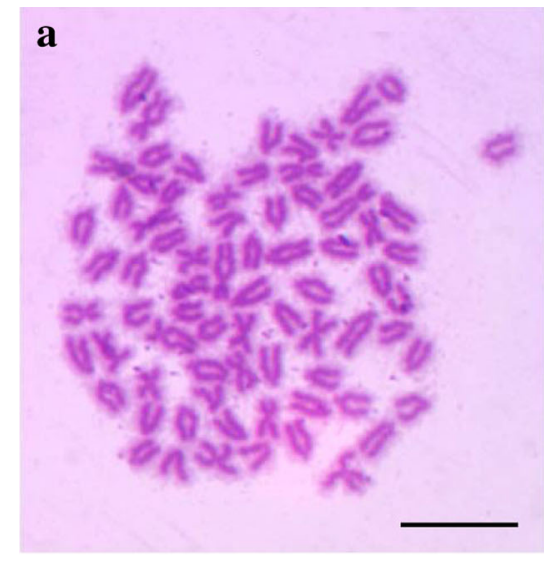

\section{b}

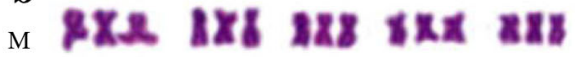

sм III

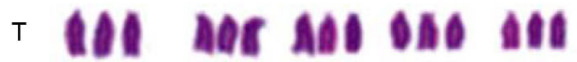

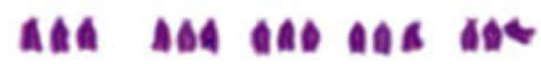

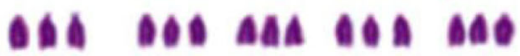

1A4 IAR MAB
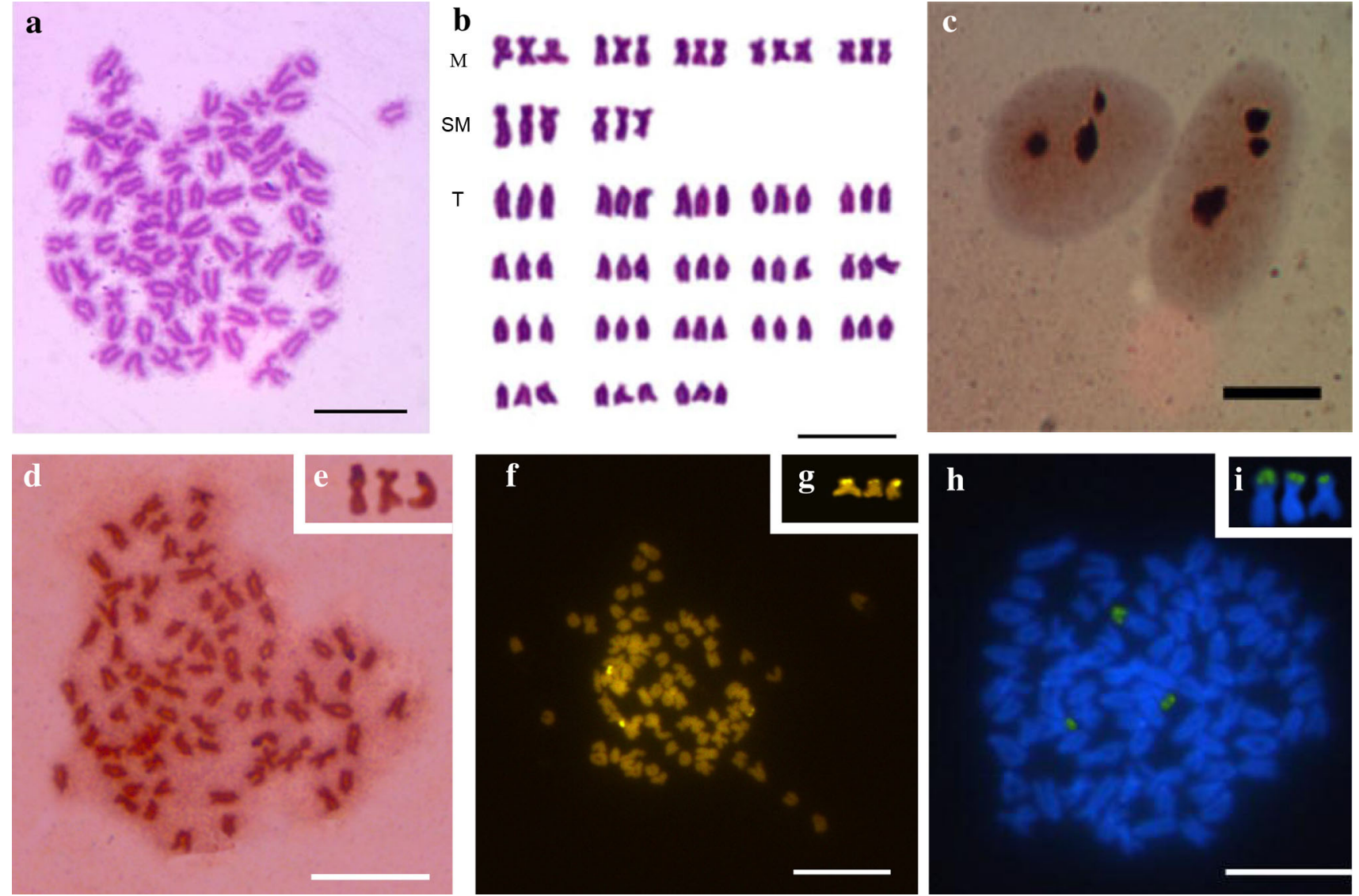

Fig. 2 Conventional Giemsa-stained metaphase (a); karyotype (b) including five metacentric (M), two submetacentric (SM), and 18 telocentric $(\mathrm{T})$ triplet chromosomes; presence of three nucleoli shown by Ag-NOR in static cells (c); silver nitrate stained metaphase (d); its partial karyotype showing Ag-NOR on short arms of the largest metacentric chromosomes (e); $\mathrm{CMA}_{3}$ stained metaphase (f); its partial

karyotype showing $\mathrm{CMA}_{3}$ positive site on short arms of the largest metacentric chromosomes (g); FISH metaphase probed by rDNA sequences (h); its partial karyotype showing rDNA loci with FISH signals on short arms of the largest metacentric chromosomes (i). Scale bar $10 \mu \mathrm{m}$ 
Based on a good quality conventional Giemsa-stained metaphase from triploid hybrids (Fig. 2a), a karyotype comprising five metacentric (M), two submetacentric (SM), and 18 telocentric $(\mathrm{T})$ triplet chromosomes clearly indicated triploidy with three sets of homologous chromosomes (Fig. 2b). In static triploid hybrid somatic cells, maximum of three Ag-NORs were detected (Fig. 2c). In a triploid metaphase, Ag-NORs were detected on the short arms of the three largest $\mathrm{M}$ chromosomes (Fig. 2d, e). $\mathrm{CMA}_{3}$ positive sites were detected on the short arms of the three largest $\mathrm{M}$ chromosomes (Fig. 2f, g). The rDNA loci FISH signals were also detected on the short arms of the three largest $\mathrm{M}$ chromosomes (Fig. 2h, i). All of these results from differential staining and FISH, indicated that triploid hybrids had three sets of homologous chromosomes, one set from diploid wild-type and two sets from tetraploid loaches.

\section{Flow cytometry of testicular cells}

Flow cytometry was carried out on the testicular tissues taken from 15 triploid hybrid males (tetraploid $\times$ diploid). When control diploid and tetraploid males produced haploid (1C DNA content) and diploid (2C DNA content) sperm, respectively (Fig. 3a, b), 12 out of 15 triploid males produced a major peak at approximately $1.5 \mathrm{C}$ DNA content, with minor peaks at $3 \mathrm{C}$ and $6 \mathrm{C}$ DNA content (Fig. 3c). These histograms showed major production of $1.5 \mathrm{n}$ spermatozoa. While one of the 15 triploids produced two major peaks at 3C and 6C DNA content and no peak corresponding to spermatozoa was detected (Fig. 3d). Two out of 15 triploids produced a major peak at 3C DNA content and minor peaks at approximately $1.6 \mathrm{C}$ and $6 \mathrm{C}$ DNA content (Fig. 3e). A minor peak at approximately 1.6C DNA content seemed to be cell populations of either spermatozoa or spermatids.

\section{Ploidy level and chromosomes of triploid (tetraploid female $\times$ diploid male) hybrid progenies}

Chromosomes were individually counted in progenies from the $2 \mathrm{n} \times 3 \mathrm{n}-1$ (Table S2), $3 \mathrm{n} \times 2 \mathrm{n}-1$ (Table S3) and $3 n \times 3 n-1$ (Table S4) crosses (Fig. S2a-c). Embryos with a mode at the ploidy level $2.4 \mathrm{n}(\mathrm{CN} 59,60,61), 3.0 \mathrm{n}(\mathrm{CN}$ $74,75,76)$ and $2.8 \mathrm{n}(\mathrm{CN} 69,70,71)$ occurred most frequently in $2 n \times 3 n-1,3 n \times 2 n-1$, and $3 n \times 3 n-1$,

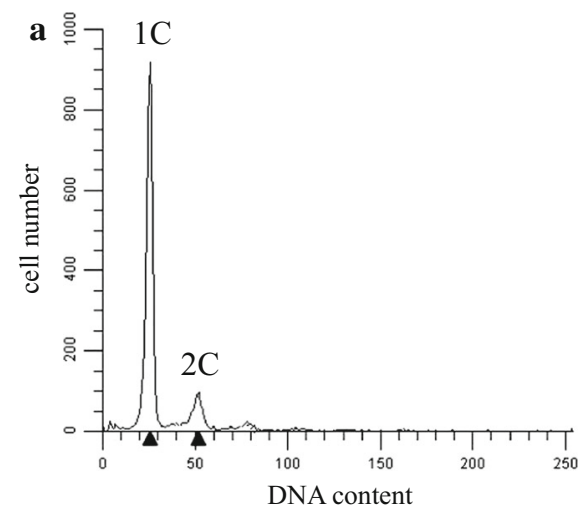

b
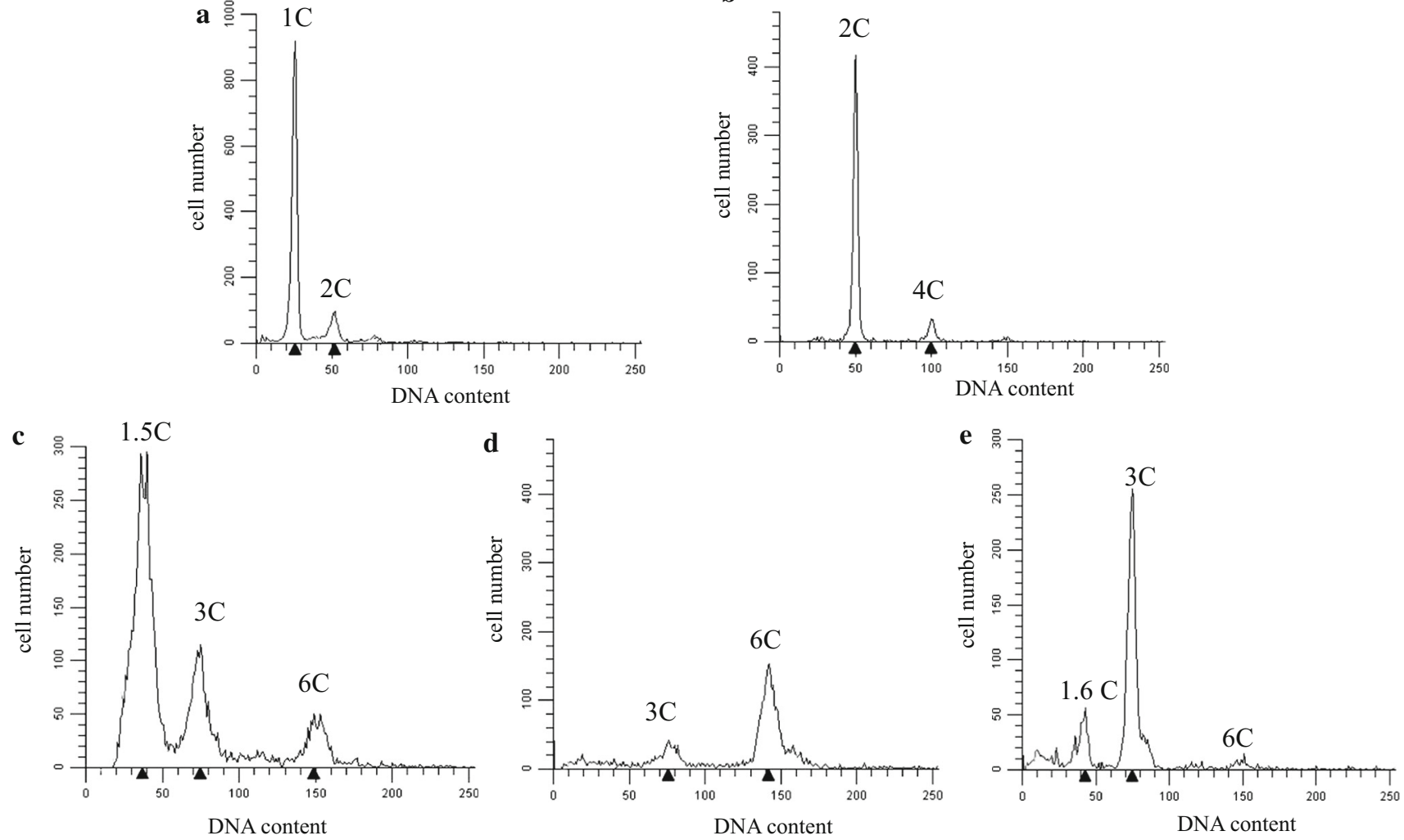

Fig. 3 Flow cytometry histograms of testicular cells taken from diploid (a), tetraploid (b), and triploid hybrid males (c-e). Note the presence of a major peak of haploid (DNA content, 1C), diploid (2C), and $1.5 \mathrm{n}(1.5 \mathrm{C})$ spermatozoa in diploid (a), tetraploid (b) and triploid

hybrid (c) males. No spermatozoa peak (d) and presence of a minor peak of 1.6n (1.6C) spermatozoa (e) in triploid males. $Y$-axis denotes cell numbers and $X$-axis denotes channel numbers in each graph 
respectively (Table S2-4). The mean chromosome numbers calculated from the cells of $2 n \times 3 n-1,3 n \times 2 n-1$, and $3 \mathrm{n} \times 3 \mathrm{n}-1$ progenies were $58.76(2.4 \mathrm{n}), 67.18(2.7 \mathrm{n})$ and $73.49(2.9 \mathrm{n})$, respectively (Fig. 4).

In the $2 \mathrm{n} \times 3 \mathrm{n}-1$ cross (Fig. 4a), 2.2n (CN 54, 55, 56: $12.4 \%), 2.3 \mathrm{n}$ (CN 57, 58: $13.7 \%$ ), 2.4n (CN 59, 60, 61: $21.9 \%), 2.5$ n (CN 62, 63: $11.7 \%$ ), and 2.6n (CN 64, 65, 66: $16.7 \%$ ) cells were predominant. Aneuploid cells with 2.1n (52, 53: 4.2 \%), 2.7n (CN 67, 68: $5.4 \%), 2.8 \mathrm{n}(\mathrm{CN}$ 69, 70, 71: $1.3 \%)$ and 3.0n (CN 74: $0.1 \%)$ occurred in lower frequencies. In the $3 n \times 2 n-1$ cross (Fig. $4 b$ ), embryos with $2.1 \mathrm{n}(\mathrm{CN} 52,53)$ to $2.5 \mathrm{n}(\mathrm{CN} 62,63)$ cells appeared at a total rate of $19.7 \%$, while $2.6 \mathrm{n}$ (CN 64, 65,

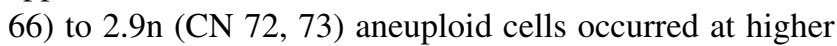
rates (total 52.1\%) (Fig. 4b). Triploids (3.0n, CN 74, 75,
76) appeared at the highest rate (14.8\%) and hyper-triploid cells $(3.1 \mathrm{n}-3.8 \mathrm{n})$ appeared at the rate of $7.3 \%$. In the $3 \mathrm{n} \times 3 \mathrm{n}-1$ cross (Fig. 4c), 2.8n (CN 69, 70, 71) to $3.1 \mathrm{n}$ (CN 77, 78) aneuploid cells appeared most frequently (total $71.7 \%$ ), but cells with less than $2.7 \mathrm{n}$ and more than $3.2 \mathrm{n}$ occurred at relatively lower rates.

\section{Ploidy level and chromosomes of triploid (diploid female $\times$ tetraploid male) hybrid progenies}

Chromosomes were individually counted in the progenies of the $2 n \times 3 n-3$ (Table S5), $3 n \times 2 n-3$ (Table S6) and $3 n \times 3 n-3$ (Table S7) crosses (Fig. S2d-f). Embryos with a mode of the ploidy level 2.5n (CN 62, 63), 2.4n (CN 59, $60,61)$, and 3.0n (CN 74, 75, 76) occurred most frequently
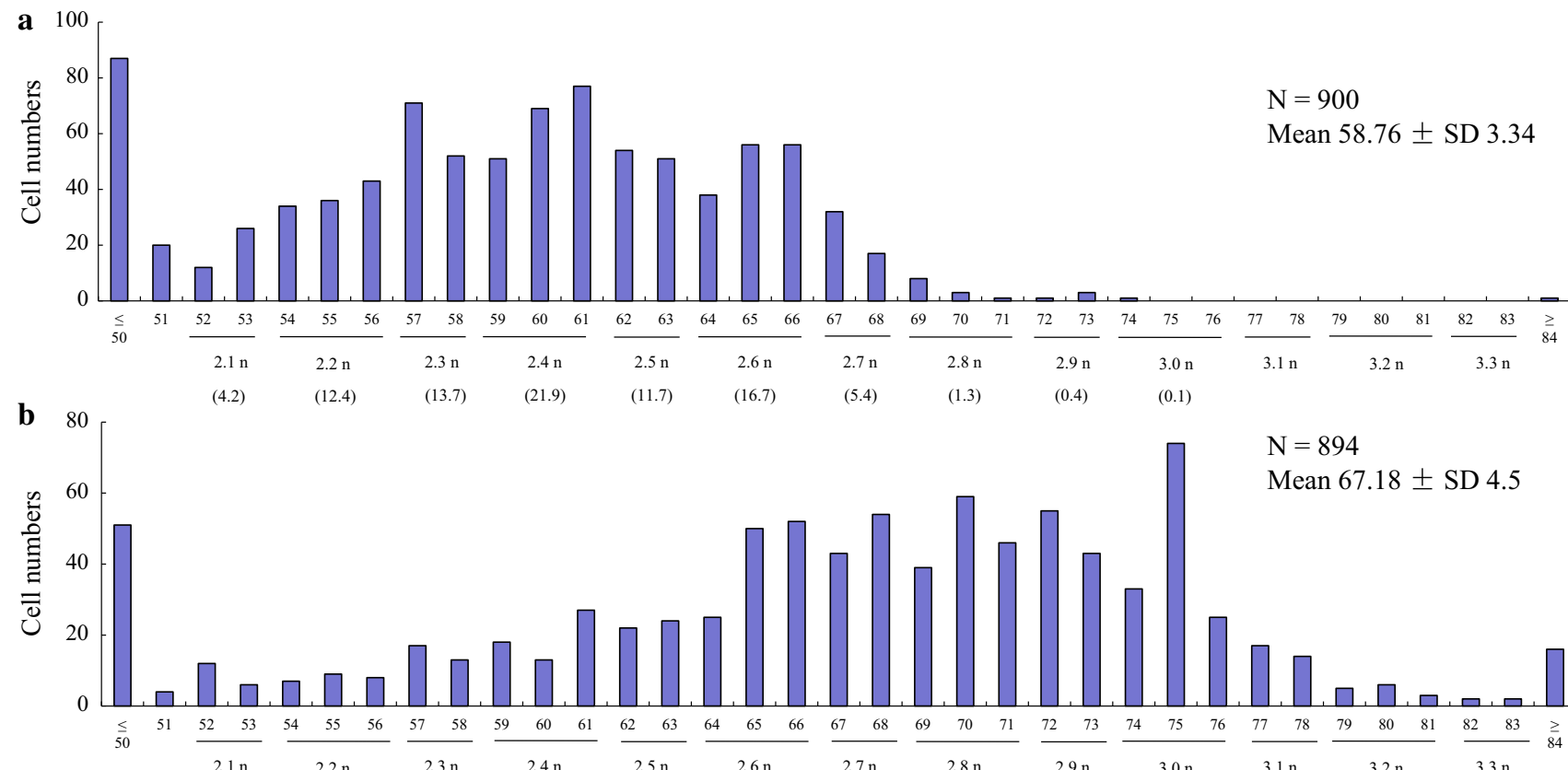

(4.2) (12.4)

$\begin{array}{llll}(13.7) & (21.9) \quad(11.7) \quad(16.7)\end{array}$

(5.4)

(1.3)

(0.4)

$(0.1)$

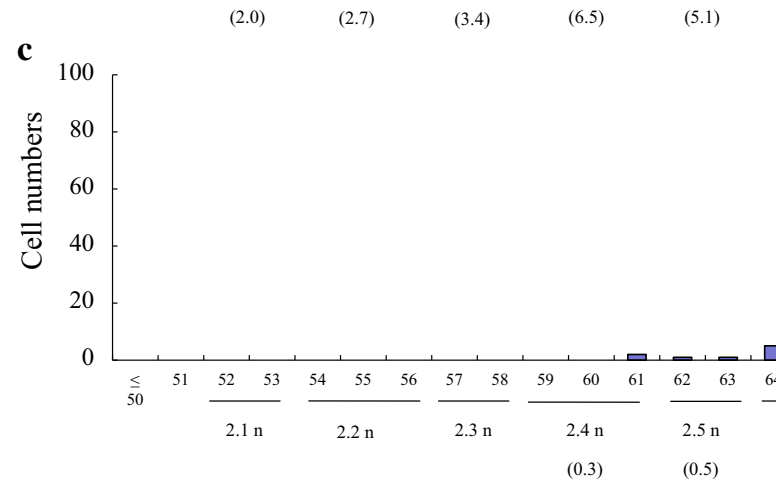

\begin{tabular}{r}
$64 \quad 65$ \\
\hline 2.6 \\
$(5.5)$
\end{tabular}

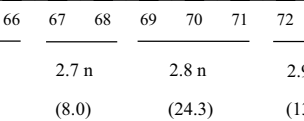

Chromosome number

Ploidy level

(Percentage)

Fig. 4 Chromosome distributions in progenies from $2 n \times 3 n-1$ (a), $3 n \times 2 n-1$ (b) and $3 n \times 3 n-1$ (c) crosses using the triploid hybrids (tetraploid female $\times$ diploid male). $Y$-axis denotes cell numbers and
$X$-axis denotes chromosome numbers and ploidy levels in each graph. Numbers in parenthesis under ploidy level indicate percentage of cells 


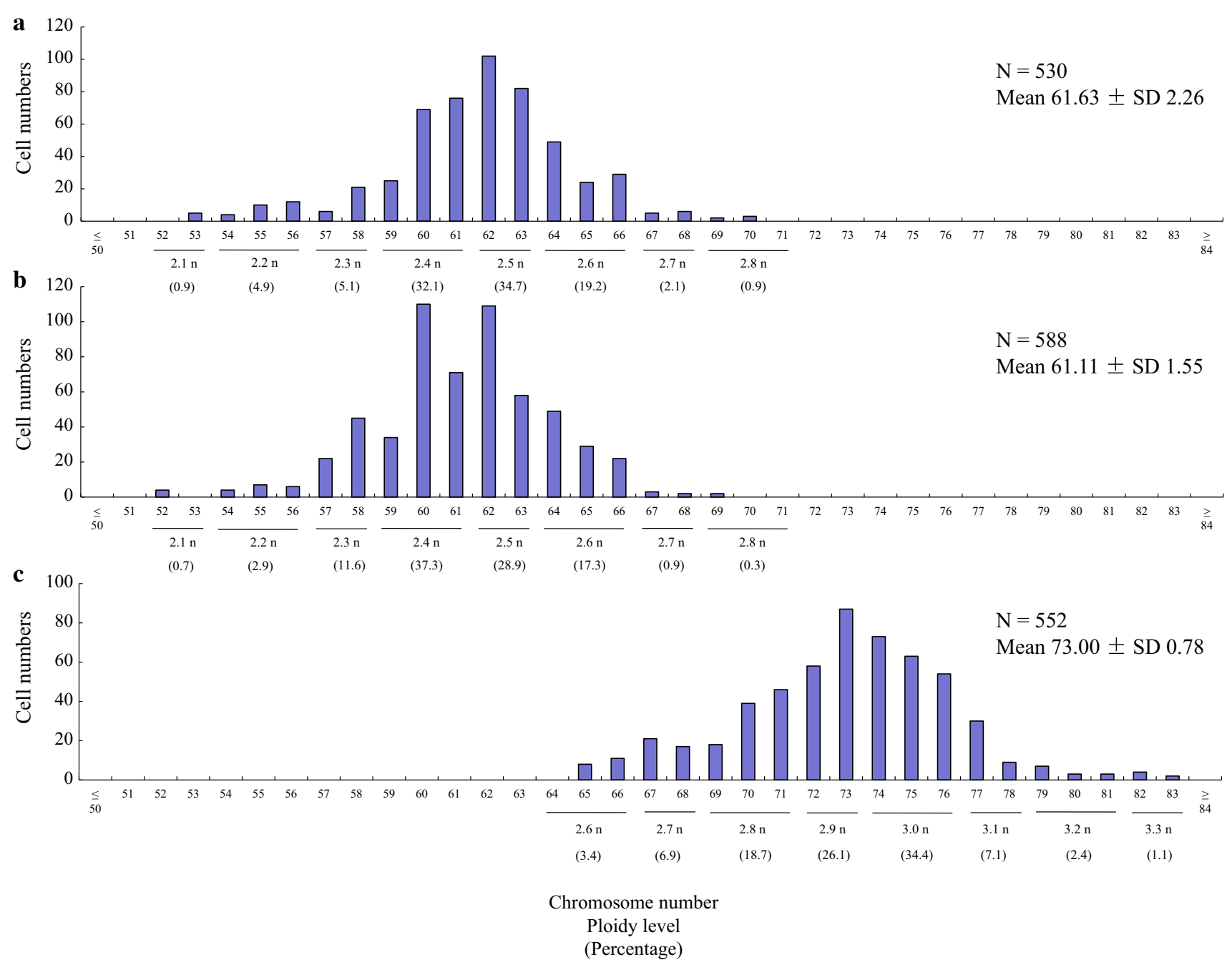

Fig. 5 Chromosome distributions in progenies from $2 \mathrm{n} \times 3 \mathrm{n}-3$ (a), $3 n \times 2 n-3$ (b) and $3 n \times 3 n-3$ (c) crosses using the triploid hybrids (diploid female $\times$ tetraploid male). $Y$-axis denotes cell numbers and

in $2 n \times 3 n-3,3 n \times 2 n-3$, and $3 n \times 3 n-3$, respectively (Table S5-7). The mean chromosome number calculated from the cells of the $2 n \times 3 n-3,3 n \times 2 n-3$, and $3 n \times 3 n-3$ progenies were $61.63(2.5 n), 61.11(2.4 n)$, and $73.00(2.9 n)$, respectively (Fig. 5).

In the $2 n \times 3 n-3$ cross (Fig. 5a), aneuploid cells with 2.5n (CN 62, 63: $34.7 \%$ ) appeared most frequently, followed by those with 2.4n (CN 59, 60, 61: 32.1\%) and 2.6n (CN 64, 65, 66: 19.2\%). The occurrence rates of other $2.1 \mathrm{n}, 2.2 \mathrm{n}, 2.3 \mathrm{n}, 2.7 \mathrm{n}$ and $2.8 \mathrm{n}$ cells were low. In the $3 n \times 2 n-3$ cross (Fig. 5b), aneuploid cells with $2.4 n(C N$ 59, 60, 61: $37.3 \%$ ) appeared most frequently, followed by those with 2.5n (CN 62, 63: $28.9 \%)$ and 2.6n (CN 64, 65, $66: 17.3 \%)$. The occurrence rates of other $2.1 n-2.3 n$ cells and $2.7 n-2.8 n$ cells were low. In the $3 n \times 3 n-3$ cross (Fig. 5c), no cells with $<2.5 \mathrm{n}$ ploidy occurred. Aneuploid cells with 3.0n ploidy level (CN 74, 75, 76: $34.4 \%)$
$X$-axis denotes chromosome numbers and ploidy levels in each graph. Numbers in parenthesis under ploidy level indicate percentage of cells

appeared most frequently, followed by those with $2.9 \mathrm{n}(\mathrm{CN}$ 72, 73: 26.1\%) and 2.8n (CN 69, 70, 71: 18.7\%). The occurrence rates of other cells were low.

\section{Discussion}

The most frequent occurrence of progenies with $2.4 n-2.5 n$ in reciprocal crosses between diploid and triploid hybrids is easily explained by fertilization of haploid gametes (1n eggs, 1n sperm) from wild-type diploids with $1.4 n-1.5 n$ gametes from triploid hybrids. The $1.5 \mathrm{n}$ gametes can be predicted by equal segregation of 25IIs formed by 25 pairs of homologous chromosomes and random assortment of the extra 25Is of 75 chromosomes in triploid, according to the binominal distribution previously reported by Zhang and Arai (1999) and $\mathrm{Li}$ et al. (2015). In the $3 n \times 3 n-3$ 
crosses, triploid to near-triploid progenies ranging from $2.6 \mathrm{n}$ to $3.3 \mathrm{n}$ with a modal ploidy level of about $3.0 \mathrm{n}$ appeared according to the expectation from the crosses between gametes with a modal ploidy level of approximately $1.5 \mathrm{n}$.

Although the appearance of $2.5 \mathrm{n}$ and $3.0 \mathrm{n}$ was also predicted in the $2 n \times 3 n-1$ (and $3 n \times 2 n-1$ ) and $3 n \times 3 n-1$ progenies, respectively, wide ranges of aneuploid cells $<2.3 n$ occurred in the $2 n \times 3 n-1$ cross. In the $3 n \times 2 n-1$ cross, frequencies of cells ranging from $2.6 n$ to $3.0 \mathrm{n}$ were much higher than the expectation. In the $3 n \times 3 n-1$ cross, frequencies of cells $<2.8 n$ ploidy and $>3$.1n were higher than those in $3 n \times 3 n-3$ cross. Such deviations from the predicted distribution based on the modal meiotic configuration might be related to the formation of diversified gametes with various chromosomes from non-typical meiotic configurations including various numbers of chromosomes, such as 24Is + 24IIs + 1III (trivalent), 23Is +23 IIs +2 2IIIs, 22Is +22 IIs +3 IIIs and so on ( $\mathrm{Li}$ et al. 2015). In our previous study, we also reported failure of synapsis between homologues and thus formation of gametes with unbalanced genetic materials was also predicted (Li et al. 2015).

Fankhauser and Hamphrey $(1950,1954)$ observed a shift toward the lower chromosome numbers in diploid $\times$ triploid axolotl progenies and suggested that this was caused by the elimination of some lagging chromosomes and the resultant failure of gametogenesis in gametes with higher numbers of extra chromosomes. A shift to lower chromosome numbers was also described in a cross between triploid and diploid rice plants (Fukui and Tsujimoto 2010). However, in the present study, a shift toward the higher chromosome numbers was found in triploid hybrid progeny $3 n \times 2 n-1$ and $3 n \times 3 n-1$ crosses. One explanation is the involvement of atypical diploid (2n) eggs generated by triploid hybrid females in such a cross-breeding. Thus, progenies might have been contaminated by unpredicted triploid embryos that arose from the fertilization of diploid eggs with haploid sperm. Oshima et al. (2005) reported the spawning of a few diploid eggs in natural triploid loaches. A similar shift of the modal ploidy level toward $2.6 \mathrm{n}-2.7 \mathrm{n}$ was recently reported in the progenies of fertile induced triploid ornamental carp (Gomelsky et al. 2015). This is presumably explained by selective mortality against eggs during oogenesis and the resultant zygotes (embryos) $<2.5 \mathrm{n}$. The other explanation for the shift to higher chromosome numbers may be the failure of gamete formation with lower numbers of extra chromosomes $(<1.5 \mathrm{n})$. However, it is difficult to apply this assumption to the shift to lower ploidy, because the modal ploidy level in progenies from the $2 \mathrm{n} \times 3 \mathrm{n}-1$ cross was $2.5 \mathrm{n}$. Flow cytometry indicated that the most frequent ploidy level of spermatozoa was approximately $1.5 \mathrm{n}$ in triploid hybrids, suggesting the production of $\sim 2.5 \mathrm{n}$ progenies after the fertilization of eggs of wild-type female.

In the present triploid hybrids, both males and females produced fertile aneuploid gametes and all progenies from the fertilization with these aneuploid gametes were inviable, probably due to deficiency and/or excess of genetic materials. These results differ from those previously reported in artificially induced triploids produced from wild-type diploids, in which triploid males generated unusual aneuploid spermatozoa, but triploid females were sterile (Zhang and Arai 1999). A part of progenies from fertilization of aneuploid spermatozoa of induced triploids were viable (Zhang and Arai 1999; Arai and Inamori 1999). In contrast, triploid hybrids between Japanese wild-type diploids and origin-unknown tetraploids from market samples were sterile in males, but females laid both meiotic haploid and unreduced triploid eggs, which produced viable progenies after fertilization with normal spermatozoa (Matsubara et al. 1995; Arai and Mukaino 1997, 1998; Zhang et al. 1998). Clone-origin natural triploids were sterile in males, but fertile haploid eggs were mainly formed in females by meiotic hybridogenesis, followed by the appearance of normal diploid embryos after fertilization with normal spermatozoa (Oshima et al. 2005; Morishima et al. 2008).

Such differences in gametogenesis and embryogenesis between present triploid hybrids and previous induced triploids or other types of triploid hybrids are likely related to the genomic constitution of resultant triploids. Genetic characteristics of Chinese loach are poorly understood and the detailed mechanisms for explaining above mentioned differences have not yet been elucidated. Thus, further genetic studies are especially required on loaches in China.

Acknowledgments This study was supported in part by KAKENHI Grant-in-Aid for Scientific Research (B) (No.21380114) from the Japan Society of the Promotion of Science (JSPS) to KA and Grantsin-Aid from the National Natural Science Foundation of China (No.31272650) and the Natural Science Foundation of Liaoning Province (No.201102019) to YJL.

\section{References}

Allen SK, Thiery RG, Hagstrom NT (1986) Cytological evaluation of the likelihood that triploid grass carp will reproduce. Trans Am Fish Soc 115:841-848

Arai K, Inamori Y (1999) Viable hyperdiploid progeny between diploid female and induced triploid male in the loach Misgurnus anguillicaudatus. Aquacul Sci 47:489-495

Arai K, Mukaino M (1997) Clonal nature of gynogenetically induced progeny of triploid (diploid $\times$ tetraploid) loach $M$. anguillicaudatus (Pisces: Cobitididae). J Exp Zool 278:412-420

Arai K, Mukaino M (1998) Electrophoretic analysis of the diploid progenies from triploid $\times$ diploid crosses in the loach $M$. anguillicaudatus (Pisces: Cobitidae). J Exp Zool 280:368-374 
Benfey TJ, Solar II, de Jong G, Donaldson EM (1986) Flowcytometric confirmation of aneuploidy in sperm from triploid rainbow trout. Trans Am Fish Soc 115:838-840

Fankhauser G, Hamphrey RR (1950) Chromosome number and development of progeny of triploid axolotl females mated with diploid males. J Exp Zool 115:207-250

Fankhauser G, Hamphrey RR (1954) Chromosome number and development of progeny of triploid axolotl males crossed with diploid females. J Exp Zool 126:33-58

Fukui K, Tsujimoto H (2010) Cytogenetics in breeding. Yokendo, Tokyo (in Japanese)

Gomelsky B, Schneider KJ, Anil A, Delomas TA (2015) Gonad development in triploid ornamental koi carp and results of crossing triploid females with diploid males. North Am J Aquacul 77:96-101

Howell WM, Black DA (1980) Controlled silver-staining of nucleolus organizer regions with a protective colloidal developer: a 1-step method. Experientia 36:1014-1015

Levan A, Fredga K, Sandberg AA (1964) Nomenclature for centromeric position on chromosomes. Hereditas 52:201-220

Li YJ, Yin J, Wang JB, Yuan X, Wei J, Sun XW, Arai K (2008) A Study on the distribution of polyploid loaches in China. Nippon Suisan Gakkaishi 74:177-182

Li YJ, Tian Y, Zhang MZ, Tian PP, Yu Z, Abe S, Arai K (2010) Chromosome banding and FISH with an rDNA probe in the diploid and tetraploid Loach, M. anguillicaudatus. Ichthyol Res 57(4):358-366

Li YJ, Yu Z, Zhang MZ, Qian C, Abe S, Arai K (2011) The origin of natural tetraploid loach $M$. anguillicaudatus (Teleostei: Cobitidae) inferred from meiotic chromosome configurations. Genetica 139:805-811

Li YJ, Zhang MZ, Qin C, Gao M, Arai K (2012) Fertility and ploidy of gametes of diploid, triploid and tetraploid loaches, $M$. anguillicaudatus, in China. J Appl Ichthyol 28:900-905

Li YJ, Yu Z, Zhang MZ, Qian C, Abe S, Arai K (2013) Induction and viable gynogenetic progeny using eggs and UV-irradiated sperm from the Chinese tetraploid loach, M. anguillicaudatus. Aquacult Int 21:759-768
Li YJ, Gao YC, Zhou H, Ma HY, Li JQ, Arai K (2015) Meiotic chromosome configurations in triploid progeny from reciprocal crosses between wild-type diploid and natural tetraploid loach M. anguillicaudatus in China. Genetica 143:555-562

Matsubara K, Arai K, Suzuki R (1995) Survival potential and chromosomes of progeny of triploid and pentaploid females in the loach M. anguillicaudatus. Aquaculture 131:37-48

Morishima K, Yoshikawa H, Arai K (2008) Meiotic hybridogenesis in triploid Misgurnus loach derived from a clonal lineage. Heredity 100:581-586

Oshima K, Morishima K, Yamaha E, Arai K (2005) Reproductive capacity of triploid loaches obtained from Hokkaido Island, Japan. Ichthyol Res 52:1-8

Schweizer D (1976) Reverse fluorescent chromosome banding with chromomycin and DAPI. Chromosoma (Berl) 58:307-324

Schweizer D, Ambros P, Andrle M (1978) Modification of DAPI banding on human chromosomes by prestaining with a DNAbinding oligopeptide antibiotic, distamycin A. Exp Cell Res 111:327-332

Ueda T, Sawada M, Kobayashi J (1987) Cytogenetical characteristics of the embryos between diploid female and triploid male in rainbow trout. Jpn J Genet 62:461-465

Ueda T, Sato R, Iwata M, Komaru A, Kobayashi J (1991) The viable $3.5 \mathrm{n}$ routs produced between diploid females and allotriploid males. Jpn J Genet 66:71-75

Van Eenennaam JP, Stocker RK, Thiery RG, Hagstrom NT, Doroshov SI (1990) Egg fertility, early developmenta and survival from crosses of diploid female $\times$ triploid male Grass Carp (Ctenopharyngodon idella). Aquaculture 86:111-125

Yoshikawa H, Morishima K, Kusuda S, Yamaha E, Arai K (2007) Diploid sperm produced by artificially sex-reversed clone loaches. J Exp Zool 307A:75-83

Zhang Q, Arai K (1999) Aberrantmeioses and viable aneuploidy progeny of induced triploid (M. anguillicaudatus) when crossed to natural tetraploids. Aquaculture 175:63-76

Zhang Q, Arai K, Yamashita M (1998) Cytogenetic mechanisms for triploid and haploid egg formation in thetriploid loach $M$. anguillicaudatus. J Exp Zool 281:608-619 